\title{
Autoradiography of Pi Distribution in Barley Seedlings
}

Satomi Kanno, Yuko Kurita, Miwa Ohnishi and Tetsuro Mimura*

Department of Biology, Kobe University, Graduate School of Science, Kobe, Japan

*For correspondence: mimura@kobe-u.ac.jp

[Abstract] Phosphorus-32 and Phosphorus-33 are radioisotopes of phosphorus. These isotopes are used to trace ionic phosphorus and phosphorus compounds. This protocol is used to follow the movement of inorganic phosphate $\left(\mathrm{PO}_{4}^{3-}\right)$ from a leaf tip to the rest of the plant.

\section{Materials and Reagents}

1. Barley seedlings

2. Radioisotopes ${ }^{32} \mathrm{P}$ or ${ }^{33} \mathrm{P}$ labeled $\mathrm{NaH}_{2} \mathrm{PO}_{4}$ dissolved in water (MP Biomedicals, PerkinElmer or American Radiolabeled Chemicals)

3. $5 \mathrm{mM} \mathrm{CaSO}_{4}$ Solution

4. Hydroponic culture solution (see Recipes)

\section{Equipment}

1. Cling film

2. $1.5 \mathrm{ml}$ plastic tubes

3. $15 \mathrm{ml}$ plastic tubes ( $1.5 \mathrm{ml}$ tube is fitted by opening a hole in the lid) (Figure 1)

4. Cotton

5. Plastic sponge

6. Imaging plate (FCR Imaging Plate for general purpose) (Fujifilm Corporation) and plate cassette (FCR standard cassette) (Fujifilm Corporation)

7. Imaging analyzer (GE Healthcare, model: Typhoon 9400 or other Radioisotope imaging analyzers)

\section{Procedure}

1. Barley plants are germinated on moist filter paper for 2-3 days and then seedlings are grown in hydroponic culture for 7-8 days.

2. Cotton is put in a $1.5 \mathrm{ml}$ tube from which the cap has been removed, then a radioisotope medium consisting of $600 \mu \mathrm{l}$ of $0.2 \mathrm{mM} \mathrm{NaH}_{2}{ }^{32} \mathrm{PO}_{4}$ (specific activity $3.7 \mathrm{MBq} / \mathrm{nmol}$ ) in 
$5 \mathrm{mM} \mathrm{CaSO}_{4}$ is added. Cotton is put enough to absorb all $600 \mu \mathrm{l} \mathrm{NaH}{ }^{32} \mathrm{PO}_{4}$. But, do not put too much cotton to keep it moisture.

3. Into the $15 \mathrm{ml}$ tube, an appropriate amount of incubation medium ( $\left.5 \mathrm{mM} \mathrm{CaSO}_{4}\right)$ is added. A barley plant sandwiched with sponge is put into the medium, and the barley leaf is manipulated into position against the plastic sponge separated from solution, such that when the smaller tube containing the cotton is mounted into a hole in the cap of the $15 \mathrm{ml}$ tube, the tip of the leaf comes into contact with the cotton soaked in radioactive medium (Figure 1).
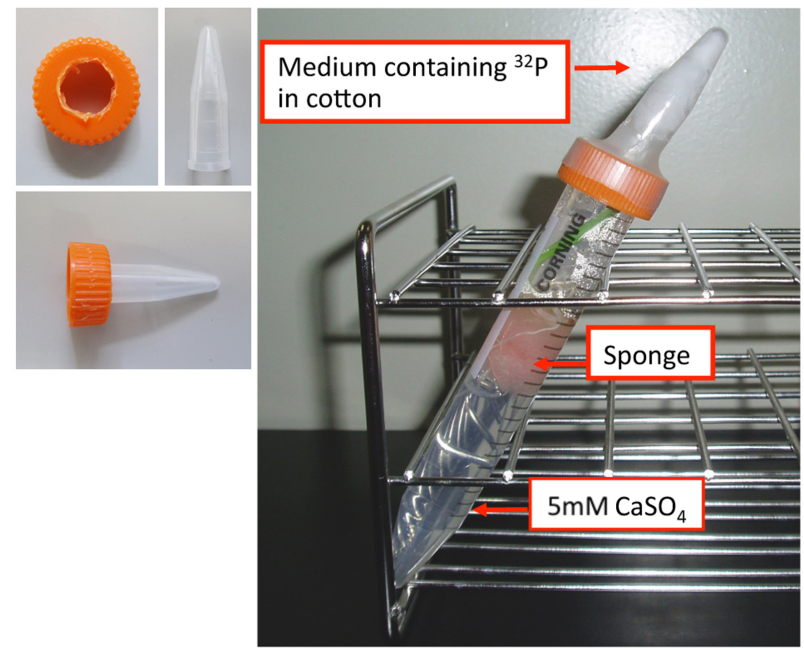

Figure 1. Setup for the radioisotopic labelling of a leaf tip

4. After an appropriate labelling period (about $2 \mathrm{~h}$ ) at 25 degrees, the sample is washed with water several times and wrapped with cling film. The sample is then set on an imaging plate and exposed (Figure 2).

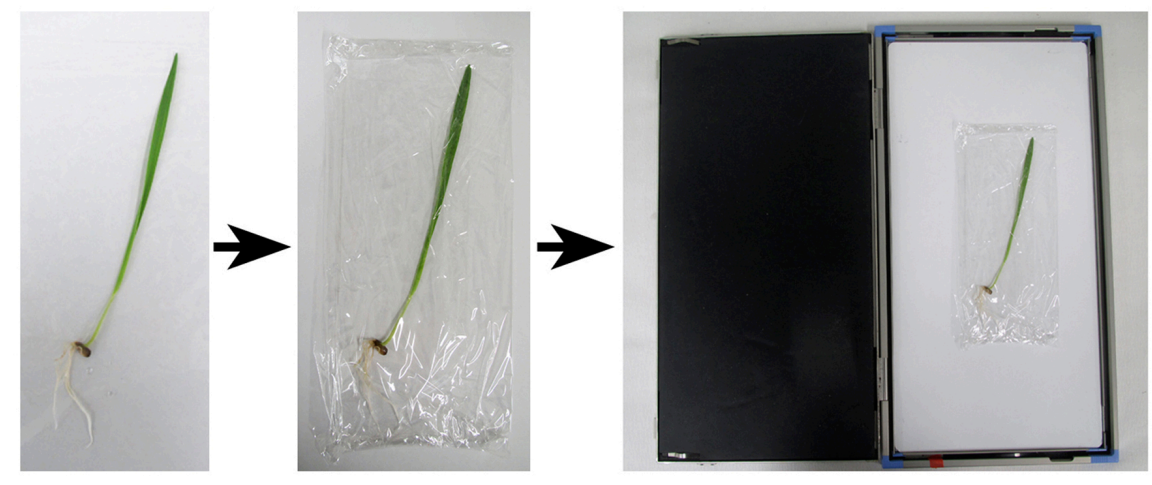

Figure 2. Setup of the radiolabeled sample on an imaging plate 
To avoid contamination of imaging plate with ${ }^{32} \mathrm{P}$, samples are wrapped by cling film. Wrapped sample is attached to the imaging plate by using binding case to expose.

5. Examine the imaging plate with an imaging analyzer (Figure 3 ). ${ }^{32} \mathrm{P}$ concentration is indicated by pseudo-color.

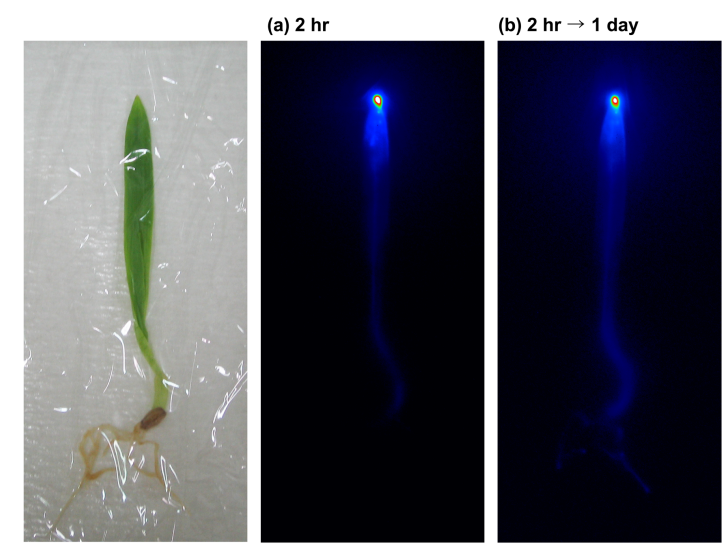

Figure 3. Autoradiogram of ${ }^{32} \mathrm{P}$ distribution in a barley plant which was radiolabeled from the leaf tip

6. Following imaging, plants can continue to be incubated in $5 \mathrm{mM} \mathrm{CaSO}_{4}$ solutions under the same light conditions for 1 or $2 \mathrm{~d}$ without cap in order to examine the movement of the radioisotope. In Figure 3 it can be seen that $\mathrm{NaH}_{2}{ }^{32} \mathrm{PO}_{4}$ absorbed at the leaf tip was translocated to the root after one day of incubation.

Figure 4 shows autoradiograms taken every 2 days following the initial incubation of roots in a Pi-deficient barley plant with an appropriate amount of incubation medium mixed $\mathrm{NaH}_{2}{ }^{32} \mathrm{PO}_{4}$ (Mimura et al., 1996)

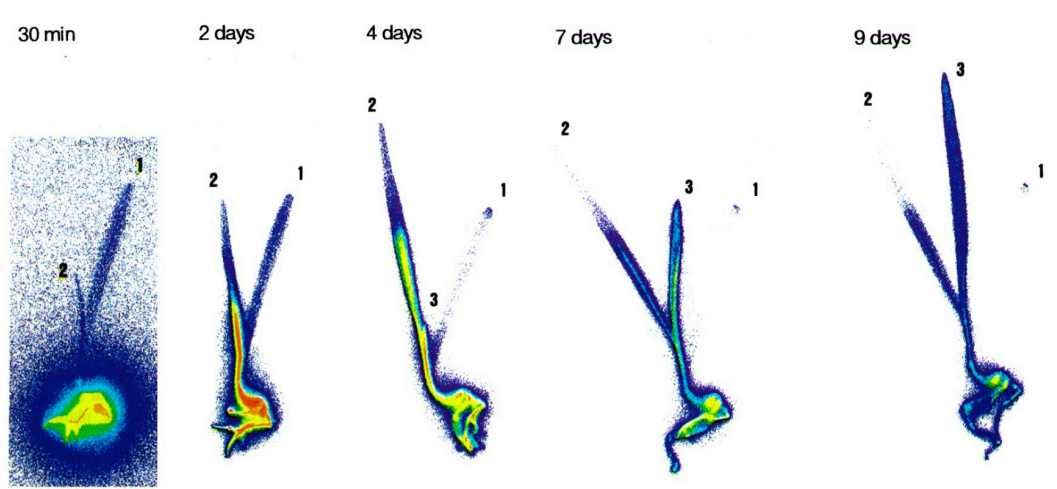

Figure 4. Autoradiogram of ${ }^{32} \mathrm{P}$ distribution in 10 days old barley plant grown in a Pi-deficient medium, which was radiolabeled from the root. The number put at the leaves in order of development. 


\section{Notes}

1. Resolution and clarity of images are strongly dependent on the radioisotope contents of plants and exposure time on the imaging plate.

\section{$\underline{\text { Recipes }}$}

1. Hydroponic culture solution

$9 \mathrm{mM} \mathrm{KNO}_{3}$

$6 \mathrm{mM} \mathrm{Ca}\left(\mathrm{NO}_{3}\right)_{2}$

$3 \mathrm{mM} \mathrm{MgSO}_{4}$

$1.5 \mathrm{mM} \mathrm{KH}_{2} \mathrm{PO}_{4}$

$0.125 \mathrm{mM}$ Fe-EDTA

Micronutrients: $\quad 10 \mu \mathrm{M} \mathrm{MnSO}_{4}, \quad 1 \mu \mathrm{M} \mathrm{CuSO}_{4}, \quad 1 \mu \mathrm{M} \mathrm{ZnSO}_{4}, \quad 30 \mu \mathrm{M} \quad \mathrm{H}_{3} \mathrm{BO}_{3}, \quad 30$ $\mu \mathrm{M}\left(\mathrm{NH}_{4}\right)_{6} \mathrm{Mo}_{7} \mathrm{O}_{24}, 0.1 \mu \mathrm{M} \mathrm{CoCl}$

\section{Acknowledgments}

This protocol was adapted from the following publications, Nagai et al. (2013) and Mimura et al. (1996). This work was supported in part by Grants-in-Aid for Scientific Research from the Ministry of Education, Culture, Sports, Science and Technology and Japan Society for the Promotion of Science (JSPS), CREST of JST (Japan Science and Technology Corporation) and in part by Hyogo Science and Technology Association. The authors also thank Yokogawa Analytical Systems Inc. for use of ion chromatography equipment.

\section{References}

1. Mimura, T., Sakano, K. and Shimmen, T. (1996). Studies on the distribution, re- translocation and homeostasis of inorganic phosphate in barley leaves. Plant Cell Environ 19(3): 311-320.

2. Nagai, M., Ohnishi, M., Uehara, T., Yamagami, M., Miura, E., Kamakura, M., Kitamura, A., Sakaguchi, S., Sakamoto, W., Shimmen, T., Fukaki, H., Reid, R. J., Furukawa, A. and Mimura, T. (2013). Ion gradients in xylem exudate and guttation fluid related to tissue ion levels along primary leaves of barley. Plant Cell Environ 36(10): 1826-1837. 